\title{
Bacteriófagos, los virus come-bacterias: historia de dos mentes científicas
}

\author{
Juan Martín Talavera-González y Martín Talavera-Rojas
}

\begin{abstract}
Resumen
El descubrimiento de los bacteriófagos (virus come bacterias) está lleno de discusiones, ya que algunos autores consideran a Felix d'Herelle como su único descubridor oficial, debido a que pudo comprobar, en 1917, que esos entes totalmente diferentes a todos los que se conocían eran los responsables de la actividad lítica (acción destructiva). En contraste, otros autores proponen a Frederick W. Twort como su verdadero descubridor, ya que, en 1915, reportó una actividad lítica; sin embargo, no pudo determinar su origen. En este artículo se relatan las observaciones, planteamientos e ideas de dos personajes que fueron pilares en el descubrimiento de los bacteriófagos, virus que actualmente son considerados como una propuesta para combatir efectivamente enfermedades mortales de origen bacteriano.
\end{abstract}

Palabras clave: descubrimiento, bacteriófagos, Twort, d'Herelle.

BACTERIOPHAGES, THE BACTERIA-EATING VIRUSES: THE STORY OF TWO SCIENTIFIC MINDS

\begin{abstract}
The discovery of bacteriophages (bacteria-eating viruses) is under discussion, some authors consider Felix d'Herelle as the only official discoverer of bacteriophages because he was able to prove, in 1917, that those entities, different from all known at the time, were responsible for lytic activity. In contrast, other authors propose Frederick W. Twort as the true discoverer, as, in 1915, he reported a lytic activity, even though he could not determine its origin. This article recounts the observations, proposals, and ideas of two individuals who were pillars in the discovery of bacteriophages, now being considered as tools to effectively combat deadly diseases of bacterial origin.
\end{abstract}

Keywords: discovery, bacteriophages, Twort, d'Herelle.

Recepción: 12/01/2021. Aprobación: 21/04/2021. Dol: http://doi.org/10.22201/cuaieed.16076079e.2021.22.5.9 
Doctor en Ciencias Agropecuarias y Recursos Naturales, Universidad Autónoma del Estado de México, Facultad de Medicina Veterinaria y Zootecnia. Profesor horas clase en Educación Media Superior. Investigador independiente en áreas de bacteriología y virología.

\section{Martín Talavera Rojas}

talaverarojas@gmail.com orcid.org/0000-0003-0908-985X

ResearchGate: Martin_Talavera2

Doctor en Ciencias Pecuarias. Responsable de las áreas de diagnóstico de bacteriología y hematología del Centro de Investigación y Estudios Avanzados en Salud Animal de la Facultad de Medicina Veterinaria y Zootecnia, Universidad Autónoma del Estado de México. Miembro del Sistema Nacional de Investigadores, Nivel I.

\section{Introducción}

La palabra bacteriófago proviene del francés bactériophage, vocablo formado por dos elementos griegos: bacteria + fagos, "que come bacterias". Los bacteriófagos (también conocidos como fagos) son virus que infectan específicamente a bacterias, además de ser las entidades biológicas mas abundantes en el planeta tierra y encontrarse en diversos sitios, por ejemplo, en heces humanasy animales, suelo, agua, etcétera. Además, su ciclo de vida les otorga la capacidad de entrar en las bacterias patógenas (microorganismos que pueden causar enfermedades infecciosas), buscando el momento oportuno para destruirlas (Jamal et al., 2019; Dy et al., 2018).

El descubrimiento de los bacteriófagos representa uno de los avances más importantes para la medicina veterinaria y humana del siglo xx, ya que en la actualidad se les considera un eslabón en la evolución (Talavera-Gonzalez et al., 2021). De igual manera, juegan un papel muy importante en la naturaleza, pues la mantienen en equilibrio, combatiendo a las bacterias patógenas y con ello evitan que se desencadenen grandes epidemias de origen bacteriano (Salmond y Fineran, 2015). Dos grandes científicos están involucrados en su descubrimiento: Frederick W. Twort, quien planteó la hipótesis de un virus ultramicroscópico transmisible y con habilidad lítica (acción destructiva) sobre las bacterias, y Félix d' Herelle, quien afirmó, por primera vez, la presencia de un nuevo tipo de virus, que bautizó como bacteriófago, un ente transmisible y capaz de matar a las bacterias. 
Imagen 1. Frederick William Twort.

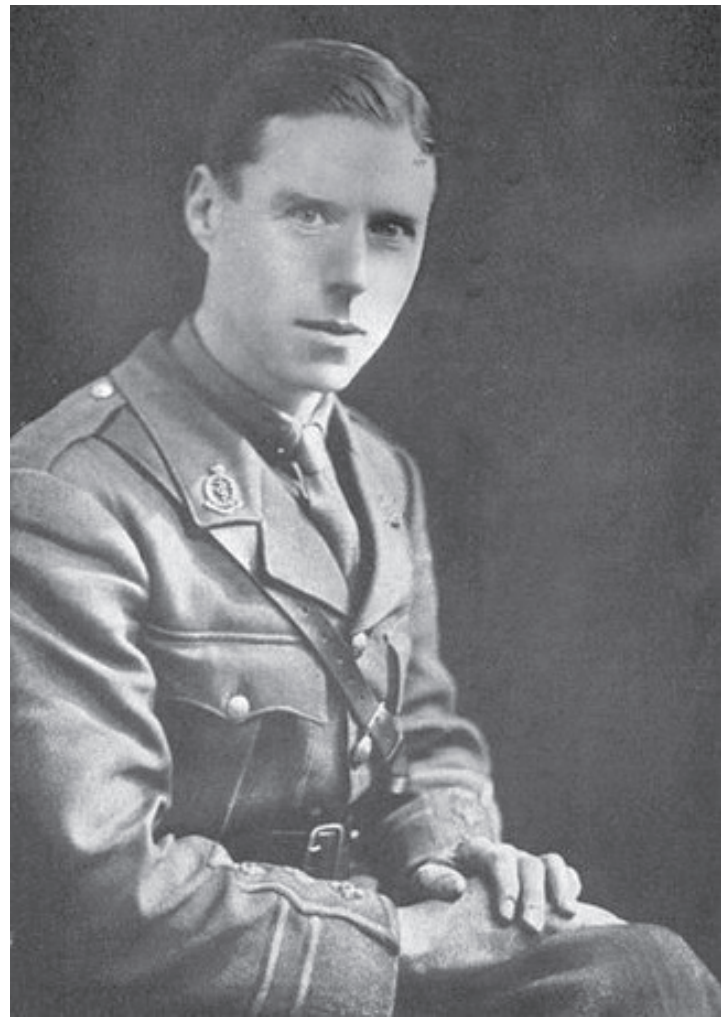

\section{Frederick William Twort}

Nació en 1877 en un pueblo inglés llamado Camberley, Surrey (ver imagen 1). Su vida estuvo llena de alegrías, aventuras, frustraciones, incertidumbre, enojo y todo tipo de emociones que puede experimentar una persona en su quehacer científico. Era el hijo mayor de un doctor, y quería seguir los pasos de su padre. Por ello, a los 16 años emigró a la ciudad de Londres para ingresar al hospital St. Thomas y dedicarse a la patología (rama de la medicina encargada del estudio de las enfermedades) (Duckworth, 1976).

En 1901 se trasladó al laboratorio de William Bulloch, donde comenzó a aportar bastos conocimientos al extraordinario mundo de la ciencia, mismos que fueron utilizados por diversos científicos especializados en microbiología (Thomas, 2014). Debido a su fama como uno de los mejores y más talentosos bacteriólogos de la región, ocupó el cargo oficial de director general del Instituto Brown, en 1909. En este lugar se brindaban servicios de medicina veterinaria, y aunque no era un sitio idóneo para realizar investigaciones, debido a la insalubridad por la cercanía con los establos, fue allí donde Twort observó por primera vez a los bacteriófagos.

Reportó sus descubrimientos en el artículo: "An investigation on the nature of ultra-microscopic viruses", publicado en la revista The Lancet en 1915 (Duckworth, 1976; Thomas, 2014). En él, describe que a pesar de su intención de propagar el virus Vaccinia, utilizado para combatir el virus de la viruela, en sus cultivos sólo crecían colonias de Micrococcus, bacterias que habitan normalmente en la piel humana y también ligadas a enfermedades en pacientes con sistema inmunológico débil.

De manera sorprendente, se percató de que las bacterias se contaminaban de unas manchas de aspecto transparente y vidrioso, con actividad invasiva, de origen no bacteriano, que además tenían la habilidad de transmitirse por varias generaciones y su actividad desaparecía cuando las sometía a una temperatura superior a $60{ }^{\circ} \mathrm{C}$. Asimismo, Twort observó que las manchas podían expandirse una vez que tocaban el cultivo de Micrococcus, lo que provocaba su completa destrucción. Lo describió así: 
"Bacteriófagos, los virus come-bacterias: historia de dos mentes científicas"

Juan Martín Talavera-González y Martín Talavera-Rojas

Vol. 22, Núm. 5, septiembre-octubre 2021

Revista Digital Universitaria

cuando un cultivo puro de Micrococcus blanco o amarillo aislado del virus Vaccinia era tocado con una pequeña porción de las colonias vidriosas, el punto tocado pronto comienza a ser transparente o vidrioso, y gradualmente se extiende sobre todo el crecimiento, matando a veces a todos los Micrococcus y reemplazándolos por gránulos finos (Duckworth, 1976; Whittebole et al., 2014; Keen, 2015; Twort, 1915).

En su artículo, Twort planteó tres posibles causas por las que aparecían las enigmáticas manchas: 1) posible manifestación inusual del ciclo de vida de la bacteria, 2) acción de una enzima producida por la propia bacteria, la cual inducía a una autodestrucción y 3) virus ultramicroscópico. Desgraciadamente, Twort no pudo afirmar ni rechazar ninguna de sus hipótesis, a causa de los recortes financieros provocados por el inicio de la primera guerra mundial en 1914 (Duckworth, 1976; Keen, 2015; Twort, 1915).

Con la intención de poder continuar con los hallazgos de las manchas vidriosas y transparentes, en 1915, Twort se enlistó en el laboratorio del Cuerpo Médico del Ejército Real en Salónica(hoyTesalónica), Grecia. Desafortunadamente, el objetivo primordial del laboratorio era realizar investigaciones de brotes epidémicos causados por la malaria (enfermedad parasitaria transmitida por mosquitos) y disentería (gastroenteritis causada por infección bacteriana o parasitaria), que estaban acabando con la vida de civiles y soldados. Durante su estancia en ese laboratorio, tuvo que luchar con las ideas arcaicas de los médicos ancianos, y desilusionado por la jerarquía médica del ejército sólo cumplió con su comisión y dos años mas tarde regresó al Instituto Brown (Duckworth, 1976).

En 1917, el científico Félix Hubert d'Herelle reportó a la academia francesa unas manchas con características idénticas a las que había observado Twort en 1915, y confirmó que eran provocadas por unos virus a los que bautizó con el nombre de bacteriófagos. Debido a este reporte, Twort se vio obligado a mandar una nota en 1921 y otra en 1925 a la revista The Lancet. En ambas manifestó que él había sido el primero en observar dicho fenómeno (Twort, 1921; Twort, 1925). En 1931, Twort fue nombrado profesor de bacteriología de la Universidad de Londres y murió el 30 de marzo de 1950.

\section{Félix Hubert d'Herelle}

Félix Hubert d'Herelle fue un microbiólogo franco-canadiense, que nació el 25 de abril de 1876 en Montreal, Canadá, y murió en París el 12 de febrero de 1949 (Duckworth, 1976; ver imagen 2). A los 17 años viajó a Inglaterra para aprender inglés y a los 18 a Alemania para asistir a la Universidad de Bonn (Duckworth, 1976; Lozano, 2007). El 11 de julio de 1893 se casó con Marie Caire, hija del cónsul francés de Estambul y en ese mismo año se integró al ejército francés, pero debido a la pasión e interés que sentía por la bacteriología desertó el año siguiente. En 1897 viajó a Quebec, Canadá, para establecer un laboratorio y comenzar algunos experimentos, lo que relata en su biografía: "era hora de que yo tomara algunas decisiones: la conclusión fue que era más sabio regresar al país donde nací... Además, siempre estaba pensando en la bacteriología, así que a mi llegada establecí un laboratorio y comencé a experimentar" (Summers, 2016). 
Imagen 2. Félix Hubert d'Herelle (Service photo Institut Pasteur Photothèque, 1905)

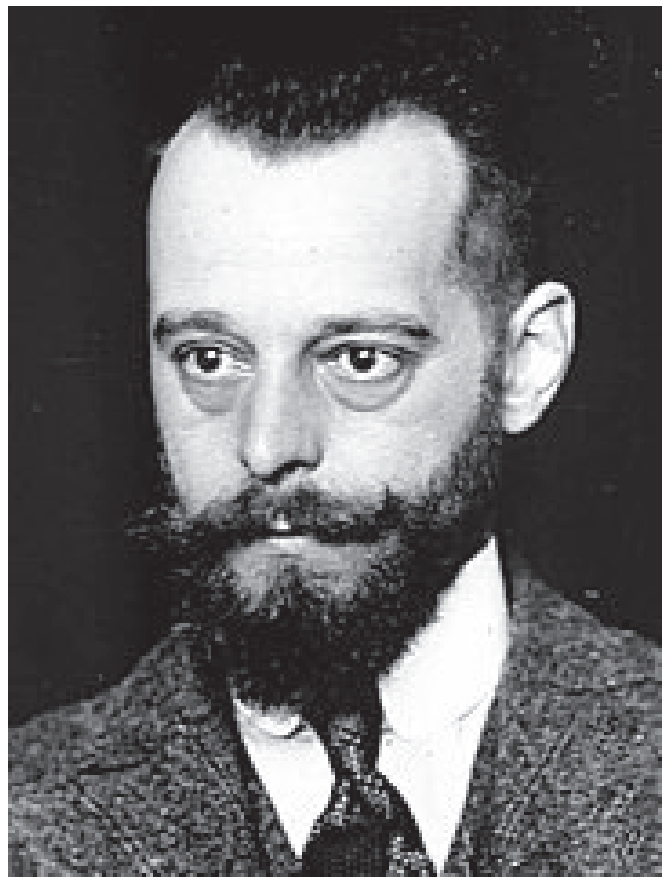

En 1908 fue contratado por la Secretaría de Fomento del Gobierno Mexicano y después de pasar por un torbellino de conflictos, entre ellos las luchas políticas por el poder y el control, instaló su laboratorio en la hacienda de Chochoh, municipio de Tixpéhual, Mérida, Yucatán. En esta hacienda se le asignó la tarea de obtener alcohol a partir de residuos de sisal (Agave sisalana), para lo cual tuvo que diseñar una maquina especial en París a expensas del gobierno mexicano.

A su regreso a México, el gobierno le ofreció la dirección de la planta destiladora, pero d'Herelle no aceptó el cargo, ya que su intención era integrarse al Instituto Pasteur. Al respecto, en su autobiografía, expresa lo siguiente: "mi misión oficial estaba terminada, el ministro me pide quedarme en calidad de director de la nueva destiladora, pero no siento ninguna vocación por semejante trabajo, ya que no se trataba de hacer investigación, por lo tanto, ya no me interesaba" (Lozano, 2007). A pesar del rechazo de la dirección, d'Herelle decidió quedarse en México un tiempo más para realizar estudios de erradicación de la plaga de langostas que había invadido los plantíos de la hacienda Chochoh (Sulakvelidze, 2001; Lozano, 2007; Lobocka y Szybalski, 2012). Su estudio culminó con la publicación: Sur une épizootie de nature bactérienne sévissant sur les sauterelles au Mexique, en 1911 (Lozano, 2007). Posteriormente, continuó con sus investigaciones en langostas en América del Sur y África del Norte, donde se percató de algunas anomalías en cultivos bacterianos, que consistían en la aparición de manchas claras en forma circular con un diámetro de 2-3 mm, pero a pesar de que las recolectó y las quiso mirar en el microscopio, no logró observar nada y supuso que era algo suficientemente pequeño que había atravesado el filtro.

En agosto de 1915, un brote de disentería hemorrágica estaba acabando con las tropas francesas en Maisons-Laffitte, París (Lobocka y Szybalski, 2012) y varios pacientes arribaron al hospital del Instituto Pasteur, los cuales fueron atendidos y estudiados por Félix d'Herelle. Durante sus investigaciones, realizó filtrados de Shigella (bacteria causante de diarrea sanguinolenta), provenientes de las heces de pacientes enfermos, con la intención de sintetizar una vacuna para combatir el brote. Fue durante esta estancia cuando d'Herelle mandó, en 1917, la nota "Sur microbe invisible antagoniste des bacilles dysentériques" a la Academia Francesa de Ciencias, en la que describe el proceso del aislamiento de 
un microbio invisible, proveniente de las heces y orina de pacientes con disentería en recuperación; además describió que este microbio combatía exclusivamente a Shigella. Fue en ese texto donde introdujo, por primera vez a la comunidad científica, el término bacteriófago obligado (Lobocka y Szybalski, 2012): "este microbio real es un bacteriófago obligado; su parasitismo es estrictamente específico, se limita a una sola especie en un momento dado" (d'Herelle, 1917).

A partir de que d'Herelle describió este hallazgo, desarrolló una amplia gama de publicaciones, en las que trató todo tipo de investigaciones en bacteriófagos. Una de las más importantes se publicó en 1922: The Bacteriophage: Its role in immunity, donde propuso la idea de utilizar a los bacteriófagos para prevenir y curar enfermedades bacterianas (Salmond y Fineran, 2015; d' Herelle, 1922).

De igual manera, en The Bacteriophage, de 1949, d'Herelle relata la capacidad destructiva de los bacteriófagos de la siguiente manera: "otro pensamiento vino a mí. Si esto es cierto, probablemente, ocurrirá lo mismo en el enfermo. En su intestino como en mi tubo de ensayo, los bacilos de disentería se habrán disuelto bajo la acción de su parásito. Ahora debe ser curado" (Kropinski, 2006). En esta misma publicación describe el momento en que observó resultados positivos en su experimentación:

a la mañana siguiente experimenté uno de esos raros momentos de intensa emoción que recompensa al investigador por todos sus dolores: a primera vista observé que el cultivo en caldo que la noche anterior había sido turbio; estaba claramente limpio, todas las bacterias habían desaparecido, se habían disuelto como el azúcar en el agua [...] lo que causó mi emoción fue que en un instante lo había entendido: lo que causó

Imagen 3. Ilustración de un bacteriófago T4 (Adenosina, 2009). las manchas claras fue un microbio invisible, un virus filtrable, un virus que parasitaba a la bacteria (Duckworth, 1976).

A pesar de que por mucho tiempo d'Herelle portó la capa y estandarte del descubrimiento de los bacteriófagos y reunió suficientes argumentos para su aplicación en la clínica humana (Kutateladze, 2015), se le negó el crédito de su descubrimiento. Se le obligó a reconocer que no había sido el primero en descubrirlos, incluso muchos autores sugieren que d'Herelle no fue honesto cuando negó tener conocimiento alguno de los trabajos realizados anteriormente por Twort. Por todo ello, la comunidad científica adoptó el nombre de fenómeno de Twort - d'Herelle y más tarde el de fenómeno del bacteriófago (Sulakvelidze, 2001; Duckworth, 1976). 
"Bacteriófagos, los virus come-bacterias: historia de dos mentes científicas"

Juan Martín Talavera-González y Martín Talavera-Rojas

Vol. 22, Núm. 5, septiembre-octubre 2021

Revista Digital Universitaria

Desafortunadamente, las investigaciones en fagos se vieron estancadas por diversos factores, como el descubrimiento de la penicilina a cargo de Alexander Fleming en 1928. Sin embargo, en Rusia, Georgia y Polonia se continuaron con investigaciones fágicas, y en la actualidad estos países son considerados como líderes en opinión y aplicación de la fagoterapia (uso de los fagos para tratar una enfermedad bacteriana) en clínica humana y animal (Kutateladze y Adamia, 2010).

\section{Conclusiones}

A más de 100 años de la introducción de los bacteriófagos en la comunidad científica, aún existe la incógnita: ¿quién es el verdadero descubridor? La paternidad de este hecho no se libera de controversias, y a pesar de que aún se desconocen muchos aspectos de los bacteriófagos, día con día, desde su descubrimiento, se han ido posicionando como candidatos para hacer frente a una posible pandemia provocada por bacterias multirresistentes (resistentes a múltiples antibióticos).

Actualmente, el uso de los fagos es megadiverso: se aplican para curar enfermedades bacterianas que los antibióticos no pueden curar, como aditivos en alimentos de mascotas, para ampliar la vida útil de productos comestibles, como herramienta de diagnóstico bacteriano, etcétera. Además, están involucrados con el descubrimiento de CRISPR (un sistema de edición genética controlada). LoS autores del presente artículo honran a las dos mentes científicas que, a pesar de las dificultades y situaciones de conflicto de su época, aportaron nuevos conocimientos, de valor inigualable, a la medicina y a la comunidad científica.

\section{Referencias}

* Adenosina. (2009). [Artistic rendering of a T4 bacteriophage]. Wikimedia Commons. https://en.wikipedia.org/wiki/File:PhageExterior.svg

- d'Herelle, F. (1917). On an invisible microbe antagonistic toward dysentery bacilli: brief note by M. F. d'Herelle, presented by Mr. Roux. Comptes Rendus Academie des Sciences, 1917;165:373-375. Bacteriophage. (2011)1, 3-5. http://dx.doi. org/10.4161/bact.1.1.14941.

* d'Herelle, F. (1922). The bacteriophage: Its role in immunity. Biodiversity Heritage Library. https://www.biodiversitylibrary.org/bibliography/31194

* Duckworth, D. H. (1976). Who Discovered Bacteriophage? Bacteriology Reviews, 40(4), 793-802.

* Dy, R. L., Rigano, L. A. y Fineran, P. C. (2018). Phage-based biocontrol strategies and their application in agriculture and aquaculture. Biochemical Society Trasactions, 46(6), 1605-1613. https://doi.org/10.1042/BST20180178

* Hankin, M. E. (1896). L'action bactéricide des eaux de la Jumna et du Gange sur le microbe du choléra. Annales de l'Institut Pasteur, 10(9), 511 - 523. 
"Bacteriófagos, los virus come-bacterias: historia de dos mentes científicas"

Juan Martín Talavera-González y Martín Talavera-Rojas

Vol. 22, Núm. 5, septiembre-octubre 2021

Revista Digital Universitaria

* Jamal, M., Bukhari, S. M. A. U. S., Andleeb, S., Ali, M., Raza, S., Nawaz, M. A., Hussain, T., Rahman, S. U. y Shah, S. S. A. (2019). Bacteriophages: an overview of the control strategies against multiple bacterial infections in different fields. Journal of Basic Microbiology, 59(2), 123-133. https://doi.org/10.1002/jobm.201800412

* Keen, E. C. (2015). A century of phage research: Bacteriophages and the shaping of modern biology. Bioessays, 37(1), 6-9. https://doi.org/10.1002/bies.201400152

* Kropinski, A. M. (2006). Phage therapy - Everything old is new again. Canadian Journal of Infectious Disease and Medical Microbiology, 17(5), 297-306. https://doi. org/10.1155/2006/329465

* Kutateladze, M. (2015). Experience of the Eliava Institute in bacteriophage therapy. Virologica Sinica, 30, 80-81. http://dx.doi.org/10.1007/s12250-014-3557-0

* Kutateladze, M. y Adamia, R. (2010). Bacteriophages as potential new therapeutics to replace or supplement antibiotics. Trends in Biotechnology, 28(12), 591-595. http://dx.doi.org/10.1016/j.tibtech.2010.08.001

* Lobocka, M. y Szybalski, W. (Eds.). (2012). Advances in Virus Research (vol. 83). Academic Press.

* Lozano, S. (2007). Félix d'Herelle. Aportes a la bibliografía de un pasteuriano en México (1904-1911). Revista Electrónica Latinoamericana de Estudios Sociales, Históricos y Culturales de la Ciencia y la Tecnología, 1. https://cutt.ly/rWYGMvy

* Salmond, G. P. y Fineran, P. C. (2015). A century of the phage: past, present and future. Nature Reviews Microbiology, 13, 777-786. https://doi.org/10.1038/ nrmicro3564

* Service photo Institut Pasteur - Photothèque. (1905). Portrait de Félix d'Hérelle, vers 1905 [fotografía]. Wikimedia Commons. https://en.wikipedia.org/wiki/File:F\%C3\% A9lix_d\%27H\%C3\%A9relle.jpg

* Sulakvelidze, A., Alavidze, Z. y Morris, J. R. (2001). Bacteriophage Therapy. Antimicrobial Agents and Chemotherapy, 45(3), 649-659. https://doi.org/10.1128/ AAC.45.3.649-659.2001

- Summers, W. C. (2016). Félix Hubert d'Herelle (1873-1949): History of a scientific mind. Bacteriophage, 6(4), e1270090. https://doi.org/10.1080/21597081.2016.127 0090

* Talavera-González,J. M., Talavera-Rojas, M., Soriano-Vargas, E., Vazquez-Navarrete, J. y Salgado-Miranda, C. (2021). In vitro transduction of antimicrobial resistance genes into Escherichia coli isolates from backyard poultry in Mexico. Canadian Journal of Microbiology, 67(5), 415-425. https://doi.org/10.1139/cjm-2020-0280

Thomas, G. (2014). Frederick William Twort: not just bacteriophage. Microbiology today, 41(2), 70-73. https://cutt.ly/XWYLMs9

* Twort, F. W. (1915) An investigation on the nature of ultra-microscopic viruses. The Lancet, 186(4814), 1241-1243. http://dx.doi.org/10.1016/S0140-6736(01)20383-3

* Twort, F. W. (1921). The discovery of the "Bacteriophage". The Lancet, 205(5303), 845. http://dx.doi.org/10.1016/S0140-6736(01)22250-8 
"Bacteriófagos, los virus come-bacterias: historia de dos mentes científicas" Juan Martín Talavera-González y Martín Talavera-Rojas Vol. 22, Núm. 5, septiembre-octubre 2021 Revista Digital Universitaria

* Twort, F. W. (1925) The ultra-microscopic viruses. The Lancet, 198(5111), 204. http:// dx.doi.org/10.1016/S0140-6736(01)32229-8

- Wittebole,X., De Roock, S.y Opal, S. M. (2014). A historical overview of bacteriophage therapy as an alternative to antibiotics for the treatment of bacterial pathogens. Virulence, 5(1), 226-235. http://dx.doi.org/10.4161/viru.25991

\section{Cómo CITAR ESTE ARTículo}

* Talavera-González, Juan Martín y Talavera-Rojas, Martín. (2021, septiembreoctubre). Bacteriófagos, los virus come-bacterias: historia de dos mentes científicas. Revista Digital Universitaria (RDU), 22(5). http://doi.org/10.22201/ cuaieed.16076079e.2021.22.5.9 